\title{
The Impact Of Employment And Physical Activity On Academic Performance
}

Giuliana Campanelli Andreopoulos, William Paterson University, USA

Eliana Antoniou, William Paterson University, USA

Alexandros Panayides, William Paterson University, USA

Evros Vassiliou, Kean University, USA

\begin{abstract}
Over the last twenty years, many contributions appeared on the relationship between working during school and academic performance using both quantitative and qualitative research methods. The obvious assumption is that a full time working student will show a lower academic performance relatively to a part time working student or a full time student. However, the empirical evidence doesn't seem to support this assumption because other variables affect the academic performance such as talent, motivation, ambition, and efficiency of studying time. We believe that the efficiency of studying time can be influenced by physical activity which paradoxically has been totally ignored in the literature. Thus, the scope of this paper is to examine the relationship between academic performance and working hours by explicitly considering the role of physical activity.
\end{abstract}

Keywords: learning, physical activity, employment, GPA, academic performance

\section{INTRODUCTION}

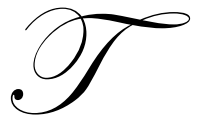

here is extensive literature on the relation between working while attending school and academic performance producing many different and controversial results. However, the role of physical activity has not been properly explored. Thus, the scope of this paper is to examine the relationship between working hours and academic performance by explicitly considering the role of physical activity. We conducted an empirical investigation based on William Paterson students (WPU) in the Fall 2007 to Spring 2007 resulting in 172 responses from business and mathematics courses.

At William Paterson University, the total number of undergraduate students is approximately 10,000 . The demographic data of WPU students can be summarized as follows: (a) Student body profile by gender: Females $58 \%$ and male 42\%; (b) Student body profile by ethnicity: Whites are the majority of the student body $63.5 \%$ followed by Hispanics 14.2\% and African Americans 12.7\%. It is worth noting that WPU recruits almost all of its full time first year students from the state of New Jersey.

\section{Questionnaire}

The study was conducted by using a questionnaire distributed to students in the classroom. The first part of the questionnaire dealt with personal data such as age, gender, student's status, marital status, number of children, weight, and height. The second part dealt with working hours and physical activities. In particular the students were asked whether they work and if the work is related to their major, if they are tired because of working, and lastly if they exercise, what type and how many hours of physical activity. The last part of the questionnaire dealt with academic performance and particularly the students were asked about their GPA, whether they expect to graduate on time, and if they are involved in any extra curriculum activities. 


\section{RESULTS}

The first set of results is summarized in Table 1. As one can see from Table 1 the percentage of part time students is the highest among the respondents. Looking at the average GPA the result seems to contradict the obvious assumption that a full time working student will show a lower academic performance relatively to a part time student or a full time student. Indeed we found that the best performance is shown by the part time working students of an average GPA of 3.4. In addition the data suggest that there is no much difference between the full time working and the non-working students. The difference is only 0.1 on the average GPA. This result is surprising and needs a more detailed investigation.

Table 1

\begin{tabular}{|c|c|c|c|}
\hline & Number of Students & \% & Average GPA \\
\hline Full time working & 40 & $23 \%$ & 3.1 \\
\hline Part time working & 110 & $64 \%$ & 3.4 \\
\hline Non working & 22 & $13 \%$ & 3.2 \\
\hline Total & 172 & $100 \%$ & 3.2 \\
\hline
\end{tabular}

Turning to non-working students the majority of them are surprisingly single men without any children. Table 2 shows that $72 \%$ of them engaged in physical activity from two hours to fifteen hours per week and with the exception of two students nobody feels tired or irritated during class time. It is widely accepted in the medical and scientific community, that exercise has a beneficial impact on brain function even though the mechanisms are poorly understood $^{1 ; 2}$. Neurotrophins, interferon gamma (IFN- $\gamma$ ) and tumor necrosis factor alpha (TNF- $\alpha$ ) are among a number of proteins shown to be important participants at the molecular level of the brain. Specifically, exercise has been shown to be beneficial in memory and learning. The hippocampus, a key area of the brain in memory formation has been studied extensively in terms of exercise and beneficial impact on memory formation. However, despite the scientific evidence and the molecular changes which occur in the brain as a result of exercise, some studies have shown that exercise does not always improve brain function ${ }^{3}$. In the particular study referenced, children with reading difficulties have been put on an exercise schedule which resulted in no improvement in reading skills. In another study involving mice though, forced exercising was shown to enchance memory formation and the number cholinergic neurons ${ }^{4}$. In a different study involving rats, running was shown to induce the proliferation of astrocytes, a type of brain cell, and neurons in the DG area of the hippocampus ${ }^{5}$. In a study involving humans with self-reported memory complaints, a 14 day healthy longevity lifestyle program which included exercise, resulted in reduction in activity of a part of the brain as assessed by brain imaging ${ }^{6}$. An important hormone that has been shown to play a key role in brain development and is produced as a result of intense exercise is the growth hormone $(\mathrm{GH})^{7}$. One can quickly come to the realization after reviewing the scientific literature that most of the scientific work is supporting the hypothesis that exercise is beneficial to the brain. What is a bit more controversial is whether that actually translates to tangible enhancements in learning, particularly in young individuals.

Table 2

\begin{tabular}{|c|}
\hline Non working students \\
\hline Gender \\
\hline $14 \mathrm{M}(63 \%)$ \\
\hline 8 F (37\%) \\
\hline Physical Activity \\
\hline Yes: $16(73 \%)$ \\
\hline No: $6(27 \%)$ \\
\hline
\end{tabular}

Turning to full time working students, as Table 3 shows, even thought there is a high percentage of students feeling tired and irritable in the classroom their relative performance is not very different from those who don't feel 
tired. Once again the difference is only 0.1 . The amount of physical activity seems to be positively correlated with the feeling of been tired.

Table 3

\begin{tabular}{|c|c|c|c|c|}
\hline Full time working students & Total & Physical Activity & Average GPA \\
\hline Feel tired & & $21(53 \%)$ & $15(71 \%)$ & 3.1 \\
\hline Sometimes tired & $11(27 \%)$ & $6(54 \%)$ & 2.9 \\
\hline No tired & $8(8 \%)$ & $3(37 \%)$ & 3.2 \\
\hline
\end{tabular}

\section{CONCLUSIONS}

In this study, our data supports the hypothesis that GPA performance is not affected by work activities. Determination and motivation seem to be the most important factors in terms of GPA performance. This is a rather surprising finding since one would expect that outside work would result in less time dedicated to course work and a negative impact on academic performance. Another interesting finding of this study is that the level of physical activity does not impact GPA performance. Based on the scientific literature available relating to exercise and brain activity, one would expect that exercise activity would likely impact academic performance in a positive manner. In this study, we do not see such a beneficial impact. There are some reports that do not support the hypothesis that exercise increases mental acuity. We did however observe a positive correlation between feeling tired and level of physical activity. One aspect we did not address in this study is whether physical activity was actually the cause of feeling tired or whether lack of sleep is responsible for feeling tired. Lack of sleep is a relatively common complaint among college students. In conclusion, our results show that academic performance is not affected by outside work activities and physical activity does not enhance GPA performance.

\section{AUTHOR INFORMATION}

Dr. Giuliana Campanelli Andreopoulos earned her Ph.D. from Cambridge University in 1990 and she is currently Professor of Economics and Director of Experiential Learning at William Paterson University.

Dr. Alexandros Panayides earned his Ph.D. from Binghamton University (SUNY Binghamton) in 2000 and he is currently Associate Professor and Chairperson of the Department of Economics, Finance and Global Business at William Paterson University

Dr. Eliana Antoniou earned her Ph.D from New Jersey Institute of Technology in 2001 and she is currently Assistant Professor in the department of Mathematics at William Paterson University

Dr. Evros Vassiliou earned his Ph.D from Rutgers State University in 2004 and is currently Assistant Professor in the department of Biological Sciences at Kean University

\section{REFERENCES}

1. Ang ET, Gomez-Pinilla F. Potential therapeutic effects of exercise to the brain. Curr Med Chem 2007; 14:2564-71.

2. Cotman CW, Berchtold NC, Christie LA. Exercise builds brain health: key roles of growth factor cascades and inflammation. Trends Neurosci 2007; 30:464-72.

3. Rack JP, Snowling MJ, Hulme C, Gibbs S. No evidence that an exercise-based treatment programme (DDAT) has specific benefits for children with reading difficulties. Dyslexia 2007; 13:97-104.

4. Ang ET, Dawe GS, Wong PT, Moochhala S, Ng YK. Alterations in spatial learning and memory after forced exercise. Brain Res 2006; 1113:186-93. 
5. Uda M, Ishido M, Kami K, Masuhara M. Effects of chronic treadmill running on neurogenesis in the dentate gyrus of the hippocampus of adult rat. Brain Res 2006; 1104:64-72.

6. Small GW, Silverman DH, Siddarth P et al. Effects of a 14-day healthy longevity lifestyle program on cognition and brain function. Am J Geriatr Psychiatry 2006; 14:538-45.

7. Aberg ND, Brywe KG, Isgaard J. Aspects of growth hormone and insulin-like growth factor-I related to neuroprotection, regeneration, and functional plasticity in the adult brain. Scientific World Journal 2006;6:53-80.

\section{NOTES}

